ELORE (ISSN 1456-3010), vol. 15 - 2/2008.

Julkaisija: Suomen Kansantietouden Tutkijain Seura ry.

[http://www.elore.fi/arkisto/2_08/kup2_08.pdf]

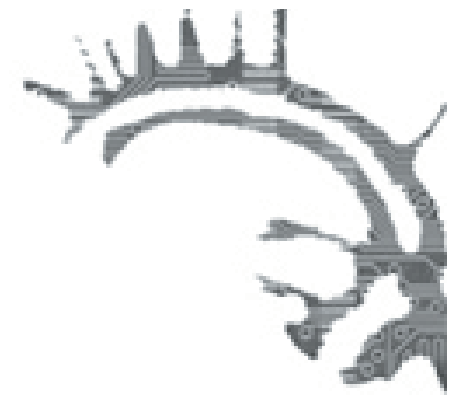

\title{
Ajankohtaista: \\ Perinteen presentaatioita ja Representaatioita: VISUAALISEN TUTKIMUKSEN ANTIA SALOMONSAARILTA
}

Kirjoitus on muokattu Joensuussa 18.3.2008 pidetystä Suomen Kansantietouden Tutkijain Seuran vuosikokousesitelmästä, jonka osana esitettiin tekijän Salomonsaarilla vuonna 2007 kuvaama lyhytelokuva Presenting Kato Bowls of Biche (5 min., Jape Films, 2008).

\section{Jari Kupiainen}

\section{JOHDANTO}

Salomonsaarten Läntiseen Provinssiin kuuluvan Marovo-laguunin eteläisin saari Gatokae on vuoristoinen tulivuorisaari, jonka asutus on 1900-luvun aikana keskittynyt rannikkokyliin. Osa kylistä sijaitsee laguunin riuttojen tai niemien suojissa, mutta saaren vanhin kylä Biche sijaitsee luonnonolosuhteiden eristämänä tuulisen avomeren rannalla. Biche on kautta historiansa tunnettu kivenveistoperinteestään, joka jatkuu katkeamattomana edelleen. Bicheläiset tunnetaan kato-astioistaan eli kivisistä "mortteleista", joissa murskataan alueen ruoka-aineista keskeisiä canarium-puiden pähkinöitä, erityisesti ngali- ja maria-pähkinöitä niistä valmistettavaa pähkinävanukasta varten. Biche on ollut läntisten Salomonsaarten ainut kylä, jossa kato-astioita on valmistettu, ja ne ovat nykyisinkin puuveiston ohella bicheläisten keskeisiä tulonlähteitä. Kato-astioita myydään Bichestä eri puolille läntisiä Salomonsaaria, erityisesti Marovo-laguunin alueen kyliin. Lisäksi niitä voi silloin tällöin ostaa myös Honiarasta, Salomonsaarten pääkaupungista. Kato-astiat leimaavat monin eri tavoin bicheläisen kulttuurista identiteettiä ja kyläläiset ovat niistä erityisen ylpeitä.

Ennen kristillistä kulttuurinmuutosta 1916, jolloin Gatokaen saarelaiset luopuivat perinteisestä uskonnostaan ja kääntyivät seitsemännen päivän adventisteiksi, pähkinätahnaa käytettiin ruoan lisäksi erilaisissa jumaluuksille ja esivanhemmille osoitetuissa rituaaleissa uhrilahjojen osana. Sittemmin pähkinätahna on säilynyt kes- 


\section{Perinteen PRESentaAtioita ja RepresentaAtioita}

keisenä ruoka-aineena etenkin niin sanottujen sapattiruokien ainesosana. Adventistien sapattiruoat valmistetaan motu-maauuneissa perjantaisin ennen sapatin alkamista. Sapattia vietetään perjantaista klo 18 lauantaihin klo 18, ja tuona aikana kaikenlainen työnteko ruoanlaittoa myöten on kielletty. Tällä tavoin kato-astioilla on kulttuurisen identiteetin ohella jatkuvaa käytännöllistä arvoa bicheläisille ja alueen muillekin adventisteille, mikä osaltaan ylläpitää kivenveistoperinnettä kylässä - siitä huolimatta, että bicheläisten kivenveistotekniikat ovat hitaita ja työläitä. Yksittäisen astian valmistaminen vie aikaa useita viikkoja tai kuukausia eikä tarjoa suurta rahallista korvausta työmäärään suhteutettuna.

Tarkastelen tässä tekstissä erityisesti seuraavia kysymyksiä: Kuinka Gatokaen saaren Bichen kylän asukkaat esittävät oman kivenveistoperinteensä ja millaisia merkityksiä he siihen liittävät? Millaista perinnettä kato-kiviastioiden tekeminen ja kivenveiston harjoittaminen ilmentävät (representoivat) alueellisesti ja kansallisesti Salomonsaarilla? Mitä Bichen kivenveistoperinne kertoo traditioiden asemasta ja luonteesta nyky-Salomonsaarilla?

Aiemmat kenttätutkimusjaksoni Gatokaen saarella ja Bichen kylässä ajoittuivat helmikuuhun 1993 ja elokuuhun 1996. Tuolloin Bichessä oli käynyt vain harvoja ulkomaalaisia eikä antropologejakaan ollut kylässä juuri vieraillut. Palatessani Bicheen marraskuussa 2007 tilanne oli muuttunut. Alueella toimivat matkailuyrittäjät toivat säännöllisesti turisteja tutustumaan saaren vanhimpaan kylään, jossa edelleen harjoitettiin "ikivanhaa kivenveistoa". Bicheläiset olivat myös kehittäneet erityisiä ohjelmanumeroita turisteja varten, esimerkiksi "perinteisen tervetulotoivotuksen". Myös antropologeja ja muita tutkijoita oli alkanut vierailla ja oleskella Bichessä. Kyläläiset olivat hämmentyneitä ulkopuolisten kiinnostuksesta ja vierailijoiden monenkirjavista motiiveista. Keskusteltuani päällikkö Harron Bilusun kanssa tilanteesta hän pyysi minua järjestämään yleisen kyläkokouksen tavoitteena selventää tilannetta kyläläisille. Kokous järjestettiin lauantai-iltana 24.11.2007 sapatin päätteeksi Bichen kirkossa, jossa kerroin sekä omasta että muiden tutkimustyöstä ja vanhan esinekulttuurin sällyttämisen tärkeydestä. Kokous toimi oman tutkimustyöni vedenjakajana Bichessä. Sen jälkeen kyläläiset päättivät järjestää minua varten - muun ohella - erityisen näytöksen kato-kiviastioiden valmistusprosessista ja minut pyydettiin kuvaamaan se videolle. Näytöstä täydensivät lukuisat haastattelut. Niissä kyläläiset varmistivat, että saisin varmasti taltioitua kaikki kato-astioiden valmistamiseen liittyvät yksityiskohdat ja katoihin liittyvät paikalliset merkitykset.

\section{Perinne ja KaStom}

Bicheläisten suhde kivenveistoperinteeseensä valottaa osaltaan sitä voimakasta kulttuurinmuutosta, jonka erityisesti kolonialistinen siirtomaahallinto (britit) ja kristillinen lähetystyö ovat Salomonsaarilla käynnistäneet, ja joka nykyaikana jatkuu osana globalisaatioprosesseja. Näiden prosessien ilmentymiä ovat vaikkapa nykyaikaiseen rahatalouteen sïrtyminen, palkkatyö, metsähakkuut, teollinen kalastus ja kaivostoi- 


\section{JARI KUPIAINEN}

minta, erilaiset kehityshankkeet sekä matkailu ja turismi, joihin paikalliset asukkaat joutuvat reagoimaan eri tavoin. Samalla paikalliset yhteisöt joutuvat olosuhteiden pakosta miettimään omien perinteidensä ja nykytilanteen välisiä suhteita. Tässä identiteettien jatkuvan uudelleenmäärittelyn prosessissa jännitteet ovat 1900-luvun ajan rakentuneet pakanuuden ja kristillisyyden, pimeyden ja valon sekä perinteisen ja modernin muodostamien käsiteparien retoriikan varaan.

Erityisesti Salomonsaarten ja laajemmin Melanesian alueen antropologisessa tutkimuksessa on käsitelty alueen perinteisiin liittyviä merkityksiä käsitteen kastom avulla (esim. Akin 1993; 2004; 2005; Burt 1994; Hviding 1996; Jourdan \& Maebiru 2002; Keesing 1992; 1994; Keesing \& Tonkinson 1982; Kupiainen 2000). Yksinkertaisesti todettuna kastom ei tarkoita samaa kuin vaikkapa englanninkieliset käsitteet "tradition" tai "customs". Kyseessä on ennen muuta paikallinen tulkinta näistä käsitteistä: ei "customs", kuten brittiläinen siirtomaahallinto olisi aikanaan halunnut lokeroida paikalliset perinteet jonkinlaiseksi menneisyyteen ja poistuviin tapakäytäntöihin liittyvänä väistyvänä ilmiönä, vaan kastom niin kuin paikalliset itse ne määrittelivät. Kastom on sitä, mitä paikalliset kulloinkin katsovat kuuluvan omaan perinteeseensä. Se sisältää myös nyky- ja viimeaikaisia kulttuuripiirteitä ja perinnepuristien mielestä epäautenttisiakin piirteitä, vaikkapa lainoja ulkomaisista kulttuureista ja teknologioista.

Kaikki kastom ei välttämättä periydy menneisyydestä. Useinkin kastomiksi nimetään melkeinpä mitä tahansa oman kulttuurikäyttäytymisen piirrettä tai paikallisia käytäntöjä, jotka kytkeytyvät yhteisön nykyhetkeen. Kastomia käytetään tällöin löyhästi "kulttuurin" merkityksessä, ja se tarkoittaa tällöin yhteisön elämäntavan piirteitä. Kastom on rajoiltaan venyvä ja tilannesidonnainen käsite, josta on muodostunut keskeinen perinnepolitiikan ja vallankäytön väline. Sillä perustellaan monenlaisia kulloinkin käsillä olevia tavoitteita, joiden katsotaan kuuluvan ryhmän intresseihin. Samalla käsitteen avulla rakennetaan erilaisia ryhmärajoja ja -identiteettejä sekä ryhmiensisäisiä ja -välisiä valtahierarkioita. Erityistä käyttöä kastom on modernisaatioprosessien paineessa saanut kytköksestä yhteisöjen sukupuolijärjestelmiin ja -järjestyksiin. Esimerkiksi Malaitan saaren Kwaio-yhteisöä pitkään tutkineen David Akinin (2004; 2005) mukaan vanhaan perinteeseen ja uskontoonsa edelleen tiukasti kiinnittyneet itäiset Kwaio-ryhmät ovat viime vuosikymmenten ajan koko ajan tiukentaneet naisiin kohdistuvia normeja ja säännöksiä kastomiin vedoten. Tällä tavoin kwaiojen modernisaatiota vastustavat ponnistukset ovat yhteisönsisäisesti kanavoituneet eritoten naisten seksuaalisuuden tiukentuneeseen säätelyyn.

Perinteen esittämisen suhteen Gatokaen saaren vanhimpana kylänä Biche sopii mainiosti edustamaan vanhaa paikallista perinnettä. Tässä suhteessa asiaa ei vesitä se tosiasia, että Seitsemännen päivän adventistikirkko on muuttanut keskeisin tavoin perinteisen elämänmuodon, arvojärjestykset ja kulttuuriset käytänteet vuodesta 1916 alkaen. Kaikki Gatokaen saarelaiset kuuluvat adventistikirkkoon, joka suhtautuu jyrkän kielteisesti kaikenlaiseen vanhaan eli esikristillisen ajan perinteeseen ja sen ilmentymiin. Esikristilliseen aikaan liittyvät perinteen representaatiot kytkeytyvät etenkin esivanhempien palvontaan, "pääkallonmetsästykseen" eli perinteiseen sodankäyntiin, magiakäytäntöihin ja rituaaliseen kannibalismiin. Kristillisenä aikana nämä representaatiot on joko pyritty hävittämään kokonaan tai niihin liittyvät tulkin- 


\section{Perinteen PRESEntaAtioIta JA RePRESEntaAtioita}

nat on etäännytetty erilaisin retorisin keinoin nykyajasta ja nykyisestä elämäntavasta. Hävittäminen on useinkin ollut konkreettista: vanhoja rituaalipaikkoja, alttareita ja pääkallokokoelmia on tuhottu heittämällä niiden esineistö mereen tai murskaamalla paikat. Lisäksi esikristillisen ajan esineistöä on vuosikymmenten ajan myyty alueella vieraileville turisteille ja artefaktikeräilijöille. Erityinen ongelma tässä laittomassa esinekaupassa ovat alueella vierailevat ulkomaiset purjehtijat, joiden veneissä esineet kulkevat viranomaisten huomaamatta vaivattomasti ulkomaille päätyen yksityiskokoelmiin. Gatokaen saarelta löytyy enää erittäin niukasti esikristillisen ajan esinekulttuuria. (Ks. Kupiainen 1999; 2000.) Lisäksi adventistit eivät ole saaneet puhua vanhoista ajoista julkisesti tai siirtää esikristillisiin käytäntöihin liittyvää perinnetietoa seuraaville sukupolville. Kun lisäksi saaren kulttuuriperinnettä ja historiaa on systemaattisesti tutkittu ja kirjoitettu julkaisuihin vasta 1970-luvulta alkaen (esim. Wall \& Kuschel 1975; kuitenkin myös Somerville 1897) ja lähinnä viimeisen vuosikymmenen ajan, paikallinen tietämys omasta perinteestä ja historiasta on ohentunut pinnalliseksi ja sirpaleiseksi kristillisen retoriikan värittämäksi tulkinnaksi menneisyydestä.

\section{Pohdintoja ja Kehityssuuntia}

Kulttuurin muutosprosesseissa Bichen kato-astioiden valmistaminen on kyennyt säilymään uskonnollisen murroksen yli nykyaikaan asti, koska se on kytkeytynyt ruokakulttuurin yhteydessä myös kristilliseen viitekehykseen eli sapattiruokien valmistamiseen. Lisäksi se on kytkeytynyt paikallisiin elinkeinoihin ja siirtynyt länsimaiseen rahatalouteen, kun astioita on alettu valmistaa myyntiin. Modernisaation ja etenkin turismin rakentumisen myötä erilaisten paikalliskulttuuristen identiteettien rakentaminen on korostunut, jolloin Bichen kyläläiset ovat rakentaneet omaa erityistä identiteettiään kivenveiston ympärille. Bicheläiset ovatkin sitoutuneet voimakkaasti tämän kivenveistoperinteen jatkamiseen, vaikka veisto näyttää tällä hetkellä olevan ikääntyvän miessukupolven toimintaa nuorten miesten keskittyessä kivenveistoa tuottoisampaan ja kevyempään puuveistoon. Kato-astioiden ja kivenveiston muut motiivit, kuten kibo-patsaat, ovat kuitenkin löytäneet tiensä myös puuveiston aiheisiin, ja nämä motiivit esiintyvät yleisesti myös bicheläisten puuveistotöissä. Tällä tavoin kato-perinne rakentaa ja artikuloi kylän omaa kulttuuri-identiteettiä erotuksena muihin Gatokaen kyliin, Marovo-laguunin alueeseen ja läntisiin Salomonsaariin.

Kato-astiat ilmentävät Bichen kastomia, joka määrittyy yhtä lailla menneisyydestä kuin nykyisyydestäkin käsin, vaikka niiden suhde esikristilliseen aikaan ja "vanhaan kulttuuriin" on sekä kiistämätön että vankka. Kato-astiat edustavat kastomia, joka on samanaikaisesti sekä päättynyttä ja etäistä esikristillistä menneisyyttä että aktiivinen ja näkyvä osa nykykulttuuria ja paikallista identiteettiä. Näin kato-astiat ilmentävät sekä päättynyttä että jatkuvaa, samanaikaisesti kiellettyä ja hyväksyttyä perinnettä. Tällä tavoin tehty kastom-määrittely mahdollistaa ensi näkemältä ristiriitaisten ja yhteen sovittamattomien merkitysten samanaikaisen läsnäolon, eikä tämä ristiriitaisuus ole pelkästään näennäistä. Silti tällaisten tulkintojen tekeminen ei kastom-puheessa ole 


\section{JARI KUPIAINEN}

mikään ongelma bicheläisille. Mieluumminkin tämä ristiriita tarjoaa diskursiivisen keinon käsitellä menneen ja nykyisen kompleksista ja osin traumaattista suhdetta.

Bicheläinen kivenveistoperinne ei kuitenkaan ole jämähtänyt perinteestä kumpuavien kiviastioiden mekaaniseen uusintamiseen ja yhä uusien astioiden työlääseen valmistamiseen. Bichen kylästä kotoisin oleva, nykyisin Penjukun kylän (Gatokae) ulkopuolella omalla pikkusaarellaan asuva Billy Vina (tunnetaan myös nimillä Bill Diver ja Billy Vinajama; s. 1934) on Salomonsaarten tunnetuin ja kansainvälisestikin arvostettu kivenveistäjä. Hän aloitti puuveistäjänä vuonna 1966, mutta vaihtoi pian kivenveistoon. Billy Vina on yhdistänyt läntisillä Salomonsaarilla esikristillisenä aikana yleisesti valmistettujen kibo-patsaiden perinteen taiteellisiin intresseihinsä ja kehittänyt oman tunnistettavan tyylin kivenveistoon. Kibo-patsaita valmistettiin muistokiviksi alttareille ja haudoille kuolleiden sukulaisten muistamista varten (ks. Kupiainen 2000). Vinan töissä esiintyvät erilaiset vanhasta perinteestä kumpuavat aiheet, kuten perinteiset simpukankuorirahat, pääkallonmetsästysaiheet ja sodankäynti, kannibalismi, kato-astiat ja amuletit. Tämä kuvasto on Vinan teoksissa muuntunut artistisiksi motiiveiksi, jotka luonnehtivat hänen tuotantonsa kokonaisuutta. Billy Vina on toiminut esikuvana, opettajana ja innoittajana läntisillä Salomonsaarilla sijaitsevan Ranoggan saaren kivenveistäjille, jotka ovat lähinnä 1970- ja 1980-luvuilta alkaen tehneet kiviveistoksia myytäväksi turisteille. Ranoggalaiset veistoaiheet esittävät useimmiten kaloja, kilpikonnia ja muita mereneläviä. Billy Vinan työt erottuvat tässä kivenveiston kentässä omanlaisinaan ja perinteisiin monipuolisesti sitoutuneina teoksina, jotka määrittelevät läntisten Salomonsaarten, Gatokaen ja Bichen traditioita nykyhetkeen sidotusti. Vinalle vanhan perinteen työstäminen taiteena on keskeinen tapa ymmärtää myös nykyaikaa.

\section{KirjallisuUS}

AKIN, DAVID 1993: Negotiating Culture in East Kwaio, Malaita. Ann Arbor: UMI Dissertation Services.

- 2004: Ancestral Vigilance and the Corrective Conscience: Kastom as Culture in a Melanesian Society. - Anthropological Theory. 4(3).

- 2005: Kastom as Hegemony? A Response to Babadzan. - Anthropological Theory. 5(1).

BURT, BEN 1994: Tradition and Christianity. The Colonial Transformation of a Solomon Islands Society. Harwood Academic Publishers. Chur.

HVIDING, EDVARD 1996: Guardians of Marovo Lagoon. Practice, Place and Politics in Maritime Melanesia. Honolulu: University of Hawaii Press.

JOURDAN, CHRISTINE with the collaboration by Ellen Maebiru 2002: Pijin. A Trilingual Cultural Dictionary. Canberra: Research School of Pacific and Asian Studies, The Australian National University.

KEESING, ROGER M. 1992: Custom and Confrontation. The Kwaio Struggle for Cultural Autonomy. Chicago: University of Chicago Press. 


\section{PerinteEn PRESENTAATIOITA JA REPRESENTAATIOITA}

- 1994: Colonial and Counter-Colonial Discourse in Melanesia (In Memoriam). Critique of Anthropology. 14:1.

KEESING, ROGER M. \& TONKINSON, ROBERT (ed.) 1982: Reinventing Traditional Culture: The Politics of Kastom in Island Melanesia. - Mankind 13(4: Special Issue).

KUPIAINEN, JARI 1999: Toto isus, Charms and Photos: Visual Ethnography on Gatokae, Western Solomon Islands. - SIGHTS - Visual Anthropology Forum [online]. $<$ http://cc.joensuu.fi/sights/jari.htm> [31.5.1999.]

-2000: Tradition, Trade and Woodcarving in Solomon Islands. Helsinki \& Højbjerg: Finnish Anthropological Society \& Intervention Press.

SOMERVILLE, BOYLE T. 1897: Ethnographical Notes in New Georgia, Solomon Islands. - Journal of the Royal Anthropological Institute of Great Britain and Ireland 26.

WALL, LINDSAY \& KUSCHEL ROLF 1975: Burial Customs and Grave Sites on Pre-Christian Nggatokae, Western Solomon Islands. - Archaeology and Physical Anthropology in Oceania. 10(1).

Filosofian tohtori, dosentti Jari Kupiainen toimii yliopettajana Pohjois-Karjalan ammattikorkeakoulun viestinnän koulutusohjelmassa.

\section{SUMMARY:}

Biche village on Gatokae Island in the western Solomon Islands is known for its continuing stone carving tradition of kato bowls (mortars). The stone bowls are used in breaking Canarium nuts into paste, which is used in local dishes. Before the local conversion to Christianity in 1916, the nut paste was used as food, and in rituals given as sacrificial offerings to extraneous forces and ancestors. Throughout the adjacent Marovo Lagoon and neighbouring regions, Biche was the only village to manufacture the stone mortars, and they were traded throughout the region. Even today, kato bowls are used by present villagers on Gatokae and Marovo in the weekly preparation of Seventh Day Adventist Sabbath dishes for Saturdays. During the field study in Biche in 2007, the villagers decided to present the different stages of kato carving for the author's video documentation, and the video, "Kato Bowls of Biche" is included with this paper illustrating the villagers' presentation of kato production. Today, Biche witnesses a modest arrival of tourists in the village, and the stone bowls attract attention also in the craft trade, but for villagers themselves, kato carving is a source of self-esteem and a cornerstone of local cultural identity, although a few earn a modest living by carving them. Bowls and other traditional stone carving motifs, such as the kibo ancestral statues, have also found their way 


\section{JARI KUPIAINEN}

in present arts and sculpture. Especially the Biche-originated Billy Vina (also Billy Vinajama, Bill Diver, b. 1934) has become internationally famous as stone and wood carver using local traditional motifs in art. The discourses of tradition and cultural identity in the Solomon Islands suface locally as discourses of kastom, widely discussed also by anthropologists. Issues of kastom and cultural representation in Biche and the Solomon Islands are discussed in the conclusion. 